\title{
4. THE FELDENKRAIS METHOD IN THE PUPPETEER'S TRAINING FROM THE PERSPECTIVE OF NICOLAS GOUSSEFF'S HANDHELD PUPPETS WORKSHOPS
}

\begin{abstract}
Anca-Mihaela Ciofu ${ }^{111}$
Abstract: Although the Feldenkrais method is quite well-known and used in relation to dance, music, and acting, it is rather uncommon to associate it with animation theatre. The puppeteer's art is a profession that requires motor skills and sustained physical effort, which demands that the animating actor has an extended consciousness of oneself and of the space. Therefore, the Feldenkrais method can be a useful instrument in the puppeteer's education and training, as the placing of the body in a relaxed stance, one which helps in the management of pain and effort, facilitates the conscious and creative learning of animation techniques, with an emphasis on the coordination and fluidity of movement. These are learning principles of the art of animation that are successfully used by Nicolas Gousseff, an artist that was formed at ESNAM (École Supérieure Nationale des Arts de la Marionnette de la Charleville-Mézières), and who has specialized in handheld puppets and using the actor's body as a performative space for this type of animation.
\end{abstract}

Key words: the Feldenkrais method, Nicolas Gousseff, puppeteer training, handheld puppets

\section{Introduction}

The Feldenkrais method was developed by Moshe Feldenkrais ${ }^{112}$ as a form of somatic education, and even of physical therapy, which works with movement and directed attention. It aims at expanding the body's functional capacity and the improvement of motricity. By learning how to use their mental flexibility, one can assume their ability to explore, negotiate, adjust, and choose solutions for improving the efficiency of the body's movements in daily activities, high performance sports, martial arts, or performing arts (dance, theatre, music/ instrument training).

Without belonging to the world of theatre, Moshe Feldenkrais was captivated by the profession of acting. This is why he taught his method in training courses at Peter Brook's company, as the latter appreciated his work and described him as "a science-educated individual who has a perfect grasp of his domain. He has studied the moving body with a precision I have not seen

\footnotetext{
111 Lecturer PhD., "George Enescu" National University of Arts from Iaşi, Romania, email: ancazava@yahoo.com

${ }^{112}$ Moshe Feldenkrais (Doctor of Sciences, 1904-1984) was born in the small Russian town Baranovitz. He studied mathematics and, for several years, he did pioneering work on the British-administered territory in Palestine. He would later head to Paris, where he would earn a Bachelor's degree in mechanical and electric engineering, then a $\mathrm{PhD}$ at Sorbonne. There, he worked with the team led by Nobel Prize Laureate Joliot-Curie. During this time, he also met Professor Kano, the creator of the martial art style judo. With the help of the latter and of his students, he earned a black belt in judo. He founded the first judo club in France, which has almost a million members nowadays. He became famous thanks to the beneficial effects of his methods, which he calls Awareness Through Movement and Functional Integration.
} 
anywhere else. He sees the body as a whole. It is from this that he has developed his teachings, which include most of the oriental and occidental systems" ${ }^{\text {"113 }}$.

\section{Discussions}

The Feldenkrais method tries to establish a better connection between the body - "the vehicle of our intentions", and the brain - "the processor", optimizing every movement pattern by making it more efficient and more natural. There are three major aspects that rule the relation between this strategy and the actor's training: the unity of mind and body, the importance of selfimage and of associating muscular action to skeletal awareness (these principles were first formulated and developed by their author during a conference held at the first International Psychodrama Congress in Paris, in 1964) ${ }^{114}$.

It is a way of learning that implies the central nervous system. The exercises aim at improving the way the body functions, by increasing awareness of one's movements - a form of pedagogy of movement -, in contrast to manipulative theories. The method offers instruments for self-observation and it improves movement patterns, it does not focus on curing a specific illness.

In regard to Nicolas Gousseff ${ }^{115}$, I have first met him this year, at the Tony Bulandra Municipal Theatre in Târgovişte, which hosted the second International Edition on professional training in the art of animation theatre, organized by UNIMA (The International Puppetry Association). A French-born theatre person, Gousseff has developed his artistic career on three levels: that of the pedagogue, the puppeteer-actor, and that of the director. Holding the conviction that the puppet is the "actor" of pure theatre, he enrolled in the first class at ESNAM (The Superior National School of Puppetry Art).

After graduation, he joined the Philippe Genty Company, where he stayed for five years. Under Alain Recoing's influence, he developed the concept of “corps-castelet” (the actor's body used as a performance space for the puppet), which he has been spreading since 1995, at Thèatre aux Main Nues (The Bare Hand Theatre), at ESNAM (where he teaches) and all over the world. Aside from his theatre activity (he has his own company, Thèâtre Qui ${ }^{116}$ ), he has studied the Feldenkrais method, graduating a teaching practicum in 2010. In addition, he has also studied Aikido and Kyudo.

\footnotetext{
113 Apud Odette Guimond, Predarea jocului teatral la începutul secolului XXI pentru o educație somatică, in “Colocvii teatrale”, nr. 3/ 2005, p. 39.

114 Idem, p. 40.

${ }^{115}$ Born in France, in 1963. He first trained at Marcel Marceau's school of corporal mime, which he joined in 1981, and he describes pantomime as "the opportunity to say everything without uttering a single word, but with the amazement of being inside of/ belonging to a body." Having an interest in stylized-based theatrical forms, such as Kabuki or Bunraku, he studied theatrical techniques like corporal language and Baroque theatre declamation with Eugène Green, who also directed him in the performance La ruelle du divin amour (1985). He founded the Thèatre Qui company, which prizes the text and its meanings, and with which he produced Vous qui habitez le temps by V. Novarina, Sens between philosophy and performance, and recently Délire à deux by Eugen Ionesco (source: Book de la première promotion de l'ESNAM (1987-1990), Charleville-Mézières : Institut International de la Marionnette, 1990, https://www.artsdelamarionnette.eu/identite/nicolas-gousseff/)

${ }^{116}$ He founded the Thèatre Qui company, which prizes the text and its meanings, and with which he produced Vous qui habitez le temps by V. Novarina, Sens, between philosophy and performance, and recently Délire à deux by Eugen Ionesco.
} 
Back to our topic, Nicolas Gousseff uses in his workshops a series of exercises in Awareness Through Movement, specific to the Feldenkrais method, having the puppeteers lay down on the floor, with their eyes closed. Through imaginative transposition, the tasks are formulated as if they were delivered to puppets. This way, the attendants do not think of their hands as moving a certain way, or performing the sitting or rising technique, but they simply identify with the puppet. Teaching Feldenkrais' lesson with the means of animation theatre, Gousseff transforms it, so that it doesn't just focus on the flexibility and expressiveness of the hand, but rather it looks at the hand as an alter-ego, a micro-cosmos of the human being. Moreover, the French man starts his demonstration stating that "when you put the puppet on, it swallows your entire hand, it completely absorbs you. Feel the puppet's weight! Feel that it's watching you!".

And he continues by asking the attendants to bring the puppet closer to themselves, to tilt it so that it touches their sternum and it feels their breath. Then, the puppet lays on the human's chest, and the latter changes their position in an attempted closeness, an embrace, an energy exchange. Gousseff's experiment with Awareness Through Movement and Functional Integration exercises, in which he gives tasks directly to the puppets, is meaningful for the way in which Feldenkrais puts forth an open method, rather than a prescriptive technique. The French artist states that:

"What interests me in the in the creative process is the creativity of the process. Putting things in relation to each other is a system of thought. Where Feldenkrais method uplifts me is in its opening towards the proprioceptive; this fertilises lots of idea for me. I'm about to go and teach actors far better than me in Russia - what can I teach them? Nothing. But I can give them the circumstances to be better for themselves and in themselves, to come back to a state of learning. There's something I really liked that Richard Corbeil [Feldenkrais method practitioner trainer] said about 'soma' not signifying body but what the body gives to being. All the talk about comfort in Feldenkrais method annoyed me at the start, but now I understand it in in terms of the relationship between the body and being; what comfort gives to being. In the end that's all there is" ${ }^{\prime 17}$.

The attendants at Nicolas Gousseff's workshops are encouraged to feel comfortable and relaxed, so that their central nervous systems are discharged, in order to facilitate learning. The tasks usually focus on states and sensations, but there is a direct connection between the inner and the outer aesthetics, which is specific to the theatre. When you feel each segment of your body in movement or relative stillness, it is possible for you to go from an inner experience to one that communicates something to those on the outside.

Furthermore, the Feldenkrais somatic educator sees movement as a means for revealing a person's/ a character's thoughts, emotions, states, as well as a

\footnotetext{
${ }^{117}$ Apud Kristin Fredricksson, Feldenkrais and training in puppetry and material performance, in "Theatre, Dance and Performance Training”, vol. 6(2), 2015, p. 241.
} 
concrete intervention instrument for facilitating change. He considers that "the civilized man (even the actor) is often characterized by a lack of sensitivity, the ability to feel what happens inside and outside himself, and consequently a difficulty to respond in a healthy way to what happens to himself, or to achieve his most simple intentions" ${ }^{\prime 18}$.

In an article that compiles three animation theatre practitioners' opinions on the importance of using the Feldenkrais method in our art, Gousseff shares his thoughts on the value of developing skeletal awareness through movement in working with the puppet, aiming at essentializing its gestures: "I think there are Awareness Through Movement exercises which are incredible, which help really practically to visualise one's own way of functioning. If you work the whole body, every joint specifically, towards an inner understanding to the point you can construct them; what an incredible lesson in corporeal mechanics for a puppet-maker or puppeteer. Visualising and sensing the shoulder joint, or the ensemble of bones that make up the rib-cage, the suppleness that it allows, the way it can bend ... these are mechanical lessons but also completely linked to emotions and to how we look or observe. Knowing how to look. Developing this proprioceptive awareness is indispensable for the puppeteer"119.

He exemplifies by drawing attention to the fact that if you don't know how you sit down yourself, you will never be able to make a piece of cloth look like a princess standing on a throne. If you want to recreate a movement through an object, you have to start from yourself (and you can do that by using your proprioceptive sensitivity), so that you can transpose it through the puppet. This does not mean that the gesture will be identical to the natural one, as it represents the essence filled with meaning of the movement you propose.

"The articulation of objects without anything connecting them is really interesting from the point of view of modelling the proprioceptive organisation of all the segments of the body. I work with this idea a lot. It's not just proprioception but sensation, the imprints left where something was held or touched. What do I retain of my imprint, of the way I touched something? What can my hand give when it touches something? What does my hand know? What do the imprint and the grasp know? The hand is the site of all grasping, all imprints, so it's the memory of all objects. So, do we need the objects in fact? I think the naked hand is the most complex puppet [...]" ${ }^{\prime 20}$.

Regardless of that, Gousseff does not use the bare hand for his demonstrations and performances, but the handheld puppet - with a peculiar physiognomy, with a head made out of a newspaper through the papier mâché technique, a handle, a plain jacket serving as a dowel rod - which is probably one of the best animation techniques for exploring the demiurgic dimension of the puppeteer, who is one with their creation, simultaneously the actor/ the handler, and the character interpreted by the puppet/ the handled.

\footnotetext{
118 Odette Guimond, art. cit., p. 40.

119 Apud Kristin Fredricksson, art. cit., p. 241.

${ }^{120}$ Ibidem.
} 
On the other hand, the Feldenkrais strategy of concentrating at the same time on local and global movement fits with the concept of "corps-castelet", in which the actor's body works as a basis, a stage for the animated character. The puppeteer tries to slip away from the spectator's awareness, to "disappear" without hiding, in order to serve the protagonist, who acts in the foreground. From this point of view, we can state that the method used by Nicolas Gousseff starting from the Feldenkrais system simultaneously follows the onstage absence and presence of the actor and the puppet. The impact on the audience stems from the effect of the play of contrasts between the lifelike object and the actor's body, which becomes an inert material, a mere scenography element.

This is why, during his demonstration, Gousseff uses a series of imagination exercises in which the puppets first interact with the actor's still body (which does not react), and then become aware and interact with each other, up to the absurd situation of trying to get close to each other, reaching and/or jumping, pushing or pulling the handler's body. We consider it is important to mention that, by maintaining the position on the floor, leaning on his elbow, the artist-teacher uses a simple change of context to trump the pain or the "blockage" that usually appear in a couple of minutes of keeping the handheld puppet in its classical position, on the screen. This way, even the people who have no training in handling on the screen can effortlessly maintain the puppet's verticality.

The strategy is in harmony with "the principle of restoration of the actor's potentiality" from Feldenkrais' method, who believed that "it is the teacher's responsibility (and competence) to invent the right learning situations, in which the student develops an unsuspected potentiality through the gradual increasing of the repertoire of their possibilities. Ceaselessly confronting your own limits and pains means ceaselessly learning that it is painful to feel powerless and, therefore, risking to become more and more helpless. Isn't it true that, unfortunately, this situation is often seen in schools?" ${ }^{121}$. When it comes to his own demonstration, which is done on a fragment from Moliere's The Miser, or when he keeps changing the position of his body, transformed into a stage, an everchanging background for the puppet-character, Nicolas Gousseff spares no effort. The ease with which he does and maintains these changes is the proof of a well-trained body.

\section{Conclusions}

Returning to the matter of the benefits of practicing the Feldenkrais method combined with puppetry, the artist speaks about the "astonishing sensations" he had during some of the training sessions he attended as a practitioner of this method, and about developing his self-awareness when he was in the situation of being moved by something, "feeling yourself more when you are moved, than when you move yourself."

\footnotetext{
${ }^{121}$ Odette Guimond, art. cit., p. 42.
} 
In order to make a point, he draws a parallel between skiing, a sport in which "you are moved by a slope", and certain Functional Integration exercises, in which "there is a special quality of sensation because you are being moved you do not move yourself". The revelation of these practices has been proven by the "amazing availability" he discovered while working with the puppet's weight after he had practiced the Feldenkrais method. The main ingredient of the puppeteer's training he had discovered was the understanding and the discovery within himself of unknown resources for working with the puppet's weight in a similar way to working with the weight of his own body. Gousseff ends his plea and his demonstration by concluding that: "We move the puppet and in a way the puppet moves us [...] That's when you become really good" ${ }^{\text {"122 }}$.

\section{Bibliography}

1. Fredricksson, K., (2015), Feldenkrais and training in puppetry and material performance, in “Theatre, Dance and Performance Training”, vol. 6(2) 2. Guimond O., (2005), Predarea jocului teatral la începutul secolului XXI pentru o educație somatică, in "Colocvii teatrale", nr. 3, Editura Artes, Iași

${ }^{122}$ Apud Kristin Fredricksson, art. cit., p. 242. 